\title{
Effects Of Financial Controls On Financial Management In Kenya's Public Sector: A Case Of National Government Departments In Mirangine Sub-County, Nyandarua County
}

\author{
John Wachira Wakiriba, Mr. Solomon Ngahu, Mr. Juma Wagoki, \\ JKUAT, Department of Business Administration P.O Box, 12-20124 Mirangine, Kenya \\ Lecturer, JKUAT, Department of Business Administration Lecturer, JKUAT Department of Business \\ Administration,
}

\begin{abstract}
This study sought to establish the effect of control activity on financial management in Mirangine Sub County of Nyandarua County. The study adopted a descriptive design and targeted 30 accounting, finance and administrative staff in the government departments in Mirangine Sub County. The study employed a census survey where all members of the target population constituted the study sample. A structured questionnaire was used to collect data. Both descriptive and inferential statistics were used in data analysis. The study findings were presented in the form of tables and figures that captured both descriptive and inferential results. The study concludes that the public sector in Mirangine Sub County has an effective internal control system characterized by clear separation of roles, supervision and commitment of management. However, there are weaknesses in the implementation of financial controls since internal audit function is not well extended to all the departments. On financial management, the study concludes that the prudential use of financial resources in Mirangine Sub County is not appropriate although there is improved asset use and classification of revenues and expenditures. The final conclusion of this study is that there is a significant positive relationship between control activities and financial management. The study recommends competence staff profiling, establishment of information system within the departments and improving the generation of more finances for the operations of the government departments.
\end{abstract}

Key Words: Audit Arrangements, Financial Controls, Financial Control Systems, Financial Management, Internal controls, Activity Controls

\section{Introduction}

Financial resource is considered as an important resource to many institutions and establishments (Allis, et al, 2004). This means that it must be effectively and efficiently managed to bring about the needed change and results from the activity for which the funds have been made available. However, sometimes this important resource is mismanaged and misappropriated by those put in charge (Rosen \& Gayer, 2010). According to Prowle (2010) public sector organizations deal with large amounts of public funds and operate in a largely political environment, thereby necessitating a need for a high degree of confidence in the way in which their financial affairs are being conducted. Furthermore, all other aspects of finance management in the public sector should be done prudently. According to Rosen and Gayer (2010) these feelings towards government are inextricably bound up with its taxing and spending activities.

Financial control is defined as the procedures designed to protect assets and ensure that all financial transactions are recorded to prevent and reduce errors and fraud (Block \& Geoffrey, 2008). The aim of financial controls is to provide an overall guiding framework for a sound and efficient management of resources in all institutions. The goal of having a strong system of financial control is to promote the institution's ability to reach its objectives, providing reliable financial data, safeguarding assets and records, evaluating operational efficiency through budget, organizational control and encouraging adherence to prescribed policies and regulations. An institutions system of financial control has a key role in the management of risks that are significant to the fulfillment of its operational objectives. A sound system of financial control contributes towards safeguarding the stakeholders' investment and the institution's assets. Financial controls facilitate effectiveness and efficiency of operations, thus helping to ensure the reliability of internal and external financial reporting and assist in compliance with laws and regulations (Hayles, 2005).

Effective financial controls including the maintenance of proper accounting records help ensure that the institution is not unnecessarily exposed to financial risks and that the financial information is used only within the business (Hayles, 2005). This also contributes to the safeguarding of assets, including the prevention and detection of fraud (ACCA, 2010). Walters and Dunn (2001) have stated that obtaining sufficient knowledge of the internal financial controls, both information technology controls and application controls, are needed to facilitate the determination of the audit strategy and to carrying out subsequent steps. According to Khoove 
(2010) control environment is the attitudes, abilities, awareness and actions of a client personnel and particularly management in relation to control. Financial control activities are the policies and procedures that help ensure that management directives are carried out (Walters \& Dunn, 2001). Control of the financial decisions covering the organization, method, process and internal audit established by the administration in order to ensure that the activities are carried out in compliance with the purpose of the administration and determined policies and the legislation, the assets and resources are protected, accounting records are kept in an accurate and complete manner and financial and management information is produced in line and in a reliable manner (Khoove, 2010). Hence controls of the financial decisions and transactions of the public institutions related to the revenue, expenditure, assets and liabilities concerning their compliance with the budget, budget item, available applicable amount, expenditure programme, financing programme of the administration, to central government budget law and other financial legislation provisions and in terms of the utilization of the resources in an effective, economic and efficient manner (Public Financial Management Act, 2004).

In both the developed and developing countries public financial management professionals working within the public sector are concerned with improving financial management and budgeting, responding to changes in financial reporting, securing better regulation, strengthening institutions and improving management and governance and auditing fraud and corruption.

Financial management consists of all the activities concerned with obtaining money and using it effectively and efficiently (Warren, 2005). Financial management involves careful planning and efficient use of resources. Proper financial management can ensure that financial priorities are established in line with organizational goals and objectives, spending is planned and controlled in accordance with established priorities and sufficient financing is available when it is needed both now and in the future (Pride et al., 2002). It's generally recognized that most developing countries have ineffective governmental financial control system. The serious deficiency in the financial control systems in most developing countries generally recognized as the major factor which facilitate the misuse of public resources and financial corruption in these countries (ElNafali, 2008).

For example in Zambia, there has been no specific financial improvement for public sector (El-Nafbi, 2008). Historically the public sector has faced capacity constraints compounded by inadequate information process and systems. In addition, non- compliance with internal controls has lead to poor predictability of government expenditure and lack of analytical capacity. Whereas the issue for the Zambian government was the need to improve financial reporting and auditing systems, the challenges for Zimbabwe was dealing with an acute shortage of qualified professionals working within the public sector Botswana also had very similar issues to those in Zimbabwe. Although a relatively wealthy country, Botswana's public sector was challenged by its failure to match the rewards offered to professional staff by the private sector (El-Nafbi, 2008). Kenya is considered to have the largest, most diversified and innovative economy in East Africa (Karanja \& Ng'ang'a, 2014). The country has the potential to reduce poverty and increase job opportunities not only to its citizenry but also to other countries within East Africa and beyond. Kenya has made significant strides in improving the overall economic environment with a performance always above that of the Sub-Saharan Africa (SSA) average Country Policy \& Institutional Assessment (CPIA) Reports, 2006-2012. But the most unfortunate in Kenya, corruption is a key constraint towards greater growth and prosperity. Corruption assumes two forms, that is, petty corruption and large scale corruption. Large scale corruption is purchase made at inflated prices, public benefit landed out to people who are not entitled; fictitious companies being paid for contracts that they never executed and therefore value for money is not achieved on public funds. Moreover, Kenya is at a critical stage of implementing the devolved system of governance as espoused in the Constitution of Kenya 2010 (Wanjau, Muiruri \& Ayodo, 2012). In addition to introducing 47 County governments with fiscal responsibility, the Constitution also established new Public Finance Management (PFM) institutions such as the Commission on Revenue Allocation, Salaries and Remuneration Commission and Office of the Controller of Budget and expanded the mandate of the Auditor General. Additionally, the PFM Act 2012 has specified roles for the National Treasury and Parliament on PFM. Capacity building is therefore required to enable various players fulfill their PFM responsibilities. Furthermore, so as to meet the enlarged financing demands of both the National and 47 County Governments there is need for increased efficiency and effectiveness in utilization of scarce public resources (Mugambi \& Theuri, 2014). Therefore this study aims to provide useful highlights on the effects of financial controls on financial management in Kenya's public sector.

\section{Statement of the Problem}

It is argued that there may be failures to understand the impact of internal control system in public sector until the public sector runs void of financial controls. The absence of adequate financial control measures exposes the financial management of public sector to certain threats such as incorrect financial statements, loss of government assets, mismanagement of government vital documents, incorrect and unreliable financial 
records which may lead to loss of government integrity, and implementation of accounting policies inconsistent with the applicable legislation. However, there is a general perception that institution and enforcement of proper internal control systems may lead to improved financial management. It is also a general belief that properly instituted systems of financial controls improve the reporting process and also give rise to reliable reports which enhances the accountability function of management of an entity. Nevertheless, available literature indicates that in spite of elaborate system of controls in organizations, financial management has been elusive in most of these organizations (OAG, 2010). Therefore, all aspects of financial management in public sector organizations should operate in an environment where there is confidence in the veracity of the financial information being used. Hence, the public sector requires robust systems of financial controls supported by effective audit and assurance arrangements. This necessitated this study which sought to establish the effect of internal controls on financial management in public sector in Mirangine Sub County.

\section{Specific Objectives of the Study}

To examine the extent to which control activities affect financial management in the public sector in Mirangine Sub County.

\section{Significance of the Study}

The findings of the current study may help identify gaps within the systems of financial controls in public sector organizations. Consequently, the research findings may be important in addressing these gaps. The findings may also be of invaluable benefits to the management and those charged with public sector governance since they are bound to enable them streamline the systems of financial controls. Ultimately, the findings are likely to ensure improved financial management and also attainment of the public sector organizations' objectives. The study may also add to the existing knowledge regarding financial controls and financial management particularly in the public sector. The study may generate knowledge to link financial controls and financial management which may guide policy makers in the planning for the public resources. The findings of the study may be helpful to all academicians in finance and accounting, management, legal, and other pertinent fields.

\section{Scope and Limitation of the Study}

The study was conducted among accounting, finance and administrative staff drawn from the government departments in Mirangine Sub-County of Nyandarua County, Kenya. The study was undertaken between the months of August and September, 2014. The researcher encountered several challenges such as reluctance by the respondents in giving information fearing that the information sought would be used to intimidate them or print a negative image about their Sub County. To counter this, the researcher carried a pilot study to establish the possible cause of non compliance in filling the questionnaires and adjusted the questionnaire accordingly. Also the researcher encouraged the respondents to participate without holding back the information they might be having as the research instruments would not bear their names.

\section{Theoretical Review}

\section{Literature Review}

In an attempt to understand the effects of financial controls in the public sector two theories (agency theory and theory of financial control) were employed to explain the relationship between financial controls and financial management.

\section{The Agency Theory}

Agency theory describes firms as necessary structures to maintain contracts, and through firms, it is possible to exercise control which minimizes opportunistic behavior of agents.

The theory recognizes the incomplete information about the relationship, interests or work performance of the agent described as adverse selection and moral hazard. Moral hazard and adverse selection affects the output of the agent in two ways; not doing exactly what the agent is appointed to do, and not possessing the requisite knowledge about what should be done. This affects the overall performance of the relationship as well as the benefits of the principal in the form of cash residual. Other related reviews include The Sarbanes-Oxley Act of 2002 (SOX) which requires companies to report on the effectiveness of their internal controls over financial reporting as part of an overall effort to reduce fraud and restore integrity in the financial reporting process. It is further asserted that software vendors that market Enterprise Resource Planning (ERP) systems have taken advantage of this new focus on internal controls by emphasizing that a key feature of ERP systems is the use of "built-in" controls that mirror a firm's infrastructure (Morris, 2011).

Financial control is one of many mechanisms used in business to address the agency problem. Others include financial reporting, budgeting, audit committees, and external audits. Studies have shown that internal 
control reduces agency costs with some even arguing that firms have an economic incentive to report on internal control, even without the requirements of SOX. It is also argued that providing this additional information to the principal (shareholder) about the behaviour of the agent (management) may reduce the information asymmetry and lower investor risk and, therefore, the cost of equity capital. Other research has found that weaknesses in internal controls are associated with increased levels of earnings management (Chan et al., 2008; Ashbaugh et al., 2008). Earnings management is the agency problem that motivated SOX legislation in the first place, specifically earnings manipulation by Enron, WorldCom.

Financial controls have played a major role in moderating the agency problem in corporations for many years. During the 1980s, several high-profile audit failures led to creation of the Committee of Sponsoring Organizations of the Treadway Commission (COSO), organized for the purpose of redefining internal control and the criteria for determining the effectiveness of an internal control system (Simmons, 1997). The product of their work is known as the COSO Internal Control-Integrated Framework (Simmons, 1997). The framework also points out that controls are most effective when they are "built into" the entity's infrastructure (COSO, 1992) and further states that "built in controls support quality and empowerment initiatives, avoid unnecessary costs and enable quick response to changing conditions. The COSO framework plays a key role in compliance because Section 404 of the Act requires companies to include in their annual report, a separate management report on the company's internal control over financial reporting and an attestation report issued by a registered public accounting firm.

Morris (2011) separates financial controls into those that are general (entity-wide) controls from those that are specific (account-level) controls. He believes that if management was overriding control features in order to manage earnings, then one would expect to find more financial control weaknesses related to general controls, even if the specific (account-level) controls are effective. This type of behaviour should be uncovered during the audit process since this is an area of concern specifically identified in Auditing Standard No. 5, Paragraph 24, which states that "entity-level controls include controls over management override." On the other hand, a stronger argument could be made that if general controls are in place and working, then one would expect to find less Internal Control Weaknesses related to general controls. Internal controls have been incorporated into policies, rules and regulations to help organizations achieve their established objectives. This is because internal controls are meant to help an organization achieve its objectives. The COSO commission was partly instituted in response to a series of high profile scandals and business failures where stakeholders (particularly investors) suffered tremendous losses.

\section{Theory of Financial Control}

The present and future personal functions of human beings are asserted to constitute the fundamental point of reference in a theory of financial controls. This theory stipulates that existing and possible functions of financial tools for organizations are most essential. In the same light, it is stated that, payments, financial instruments, accounting, control models, economic calculations, and related considerations, both within and outside of the organization, ought to be discussed in regard to inner characteristics but also possible effects. It is noted that establishing the relationships between various activities and financial processes, from a financial control point of view, is a general and basic issue (Ostman, 2009).

The theory of financial controls for organizations places a natural focus on the firms such that they are viewed from several latitudinal areas. The first regards the human beings' functions of what is accomplished through organizations, their activities and output. The second is about the structure of the organization and activities, and of transactions that various parties have with each other. The third area covers the control systems in the sense of recurring procedures and methods that are employed to relate present and future functions to resources both externally and internally. The aforementioned financial control tools are argued to be crucial from an individual organization's perspective and also for larger economic systems. The fourth and last area illustrates the specific processes of individual organizations for certain issues. The theory further states that structure and financial control system works together (Ostman, 2009). The financial control theory is very relevant to the current study given that it assists in better understanding of the intricacies surrounding financial management in an organization.

\section{Empirical Review}

Financial control activities refer to all policies and procedures adopted by the management of an entity to aid in achieving management objectives. Financial control system provides assurance to the management of the reliability of accounting data employed in making decisions. Decisions made by management are said to become organization's policies and to be effective, the policies ought to be communicated to all pertinent stakeholders in the organization and consistently followed. According to the statement on auditing standards (SAS, 2002) control activities are the policies and procedures that help ensure that management's directives are carried out. Crawford (2000), states that until recently, this has been the historical component of internal control. 
Jajo (2005) asserts that control activities can be categorized as authorization, segregation of duties, record keeping safeguarding and reconciliations and these controls depend greatly on the activity under consideration. Hubbard (2003) argues that a great deal of activity specific knowledge is required to determine what controls should be. COSO lists some complete frameworks and can be used to model control activities such as; control objectives for information technology, system's assurance and control, total quality management and system development life cycle depending on the activities involved.

According to Warren (2003) control activities usually involve two elements; a policy establishing what should be done and procedures to effect the policy. Gwilliam and El-Nafabi (2002) argue that in general, most developing countries have ineffective government financial control systems. This is responsible for facilitating the misappropriation of public resources and financial corruption in these countries. The lack of adequate auditing and accounting systems in most African countries is exemplified by ineffective internal control and internal check, unqualified auditing and accounting staff, and unreliable and untimely accounting information systems. This has led to inadequate safeguards against corruption, fraud and other related malpractices. In Nigeria's public sector, policies are not adequately followed. Owizy (2011) assessed the effectiveness of internal control in government ministries taking a case of Benue State ministry of finance. According to the study findings, it was established that Benue State ministry of finance prepare annual budget promptly and also have adequate expenditure tracking to prevent financial recklessness. Consequently, it was recommended that, the ministry of finance should strictly abide by the principles and procedures in order to ensure that slack are built into the budget. According to El-Nafabi (2009) when studying the role of public sector audit and financial control systems in Sudan, found that audit and control system is paramount in ensuring accountability for the use of public funds, and safeguarding the limited public resources against corruption and other misappropriation and unlawful practices. The study found out that weak and ineffective financial control systems and deficiencies in accounting systems are some of facilitating factors of financial corruption in Sudan.

Alin et al. (2006) argued that financial control is achieved by designing systems and procedures to suit the specific needs of an organization. Just like in public sector's organizations, for there to be financial control and accountability of NGOs, it is crucial that an overall financial policy be put in place. In order to have effective financial control, a firm's staff and other stakeholders are supposed to be privy with and participate in the budgeting process that affects the line items for which they are held responsible (Vincent \& Emil, 2000). Wanyama (2001) studied the sustainability of CBOs in Western Kenya and found that many CBOs do not have qualified personnel, lack sufficient resources, have inefficient systems in place, and have egocentric and corrupt officials. To aggravate the situation, they are financially incapacitated to outsource auditors. Factors influencing financial control practices in community based organizations (CB0s) in Baringo County, Kenya have also been analyzed (Koitaba, 2013). The findings indicated that majority of the CBOs in the County were audited annually. However, the study suggested that there was need to ensure compliance among those to be subjected to audit at least once a year. It was further recommended that standardized accounting and reporting should be provided by the government so as to enable tractability of CBOs' financial activities through information sharing on a common and acceptable platform.

\section{Financial Management}

According to Padilla et al (2012) in their study on financial sustainability for non-profit organizations, effective financial management practices is essential in enhancing transparency, efficiency, accuracy, accountability which enable an organization to achieve its objectives. As pointed out by Hendrickse (2008), financial management should include keeping an accurate record of all financial transactions, linking the budget to the firm's strategic and operational plans. Financial management further demands that management accounts ought to be produced in order for the managers to compare their organization's progress against the budget and then make decisions about the future. More so, financial management stipulates that there should be internal controls or checks and balances in place with the object of safeguarding the organization's assets, and also to manage risk. There ought also to be an audit committee or auditor that to assist in ensuring the quality and reliability of financial information employed. El-Nafabi (2009) sought to establish the role of public sector audit and financial control systems in safeguarding public funds in Sudan. He alleged that there are a number of factors that encourage financial corruption in the public sector. He asserted that financial control systems and internal check in majority of public sector units are weak and ineffective. This is claimed to be occasioned by a shortage or lack of qualified and trained accountants as exemplified by the allegation that in a public department, all the financial activities of the concerned organization are conducted by one or two employees. In addition, there is absence of internal auditing which is a crucial component of internal control system in most government departments. In case such exists, it is very weak and ineffective (Chioccola \& Muhlstein, 2005). It is also asserted that there are deficiencies in the accounting system in most public firms. Some of the cited challenges facing public financial management system include the allegation that the entire accounting system is manual at both national level and the states, and that about half of the staff have had no formal training in 
financial management.

\section{Methodology}

The study adopted descriptive research design because such a design allows simultaneous description of views, perceptions and beliefs of the respondents at any single point in time. The study was conducted in Mirangine Sub-County. The target population constituted accounting, finance and administrative staff in Mirangine Sub-County. There were a total of 30 personnel drawn from the aforementioned departments. Census sampling was used to select the ample size where every member of the target population participated in the study. The study relied exclusively on primary data that was collected from the sampled respondents. A structured questionnaire was used to collect the data because it ensured confidentiality of the information given by the respondents. The determination of validity and reliability of the instrument was done before data collect data for the main study. The instrument was deemed reliable with Cronbach's above 0.7 (that is, $\alpha \geq 0.7$ ). Descriptive statistics was used to summarize the data through percentages and frequencies as well as measures of central tendencies and dispersion. The data was further subjected to inferential analysis through Pearson's correlation analysis to show the direction and strength of association between control activities and financial management.

\section{Effects of Financial Controls}

\section{Results And Discussion}

The study examined the effects of financial controls in the public sector based on the case of Mirangine Sub County. This section presents results obtained from the study. The findings are reported based on the objective of the study and the results presented using descriptive and inferential statistics in the subsequent sub sections.

\section{Descriptive Statistics on Control Activities}

The objective of the study sought to examine the effect of control activities on the financial management in Mirangine Sub County. Descriptive statistics were used to compute the mean and standard deviations of the results as presented in table 1.

Table 1:Mean and Standard Deviation of Control Activities

\begin{tabular}{|c|c|c|c|c|c|}
\hline Control Activities & $\mathbf{N}$ & Min. & Max. & Mean & SD \\
\hline There are clear separation of roles & 30 & 1 & 5 & 3.42 & 1.244 \\
\hline Employees' is work checked by others & 30 & 1 & 5 & 3.08 & 0.906 \\
\hline Appropriate supervision by senior staff & 30 & 1 & 5 & 3.47 & 0.893 \\
\hline Corrective action taken to address weakness & 30 & 1 & 5 & 3.21 & 1.119 \\
\hline Staff trained to implement system & 30 & 1 & 5 & 3.34 & 0.938 \\
\hline There is a well developed chart of account & 30 & 1 & 5 & 3.35 & 1.060 \\
\hline No expense is incurred in excess of budget & 30 & 1 & 5 & 3.05 & 0.998 \\
\hline Variance reports generated with explanations & 30 & 1 & 5 & 2.89 & 1.197 \\
\hline Security systems safeguards Assets & 30 & 1 & 5 & 2.51 & 1.096 \\
\hline
\end{tabular}

Source: Author (2014)

The results presented in the table above were obtained from the study regarding the effects of internal control systems in Mirangine Sub County based on control activities as a financial controls component. The results were analyzed using mean and standard deviations of the responses. The results are further discussed under the various headings of the indicators of control activities tested. These are discussed as follows;

\section{Separation of Roles among employees at Mirangine Sub County}

The results as reflected in table 1 suggest that respondents agreed that there was a clear separation of roles while executing finance management functions. This is shown by a mean of 3.42. However, a significant standard deviation of 1.244 is a clear manifestation of varied responses as far as clear separation of roles is concerned. This is in line with Ray and Pany (2001)'s suggestion of segregation of duties such that no one person should handle all aspects of a transaction in an organization. This also concurs with Jajo's (2005) recommendation that effective control activities should be categorized as authorization, segregation of duties, record keeping, safeguarding of assets and reconciliation of statements in an organization. According to Chemengich (2013) these controls depend greatly on the activity under consideration. This position has been highlighted by Hubbard (2003) who argues that a great deal of activity specific knowledge is required to determine what controls should be handled by which employee. 


\section{Internal checks within the Departments}

Results regarding whether there were internal checks as reflected in table 1 suggest that respondents were indifferent as to whether every employee's work was checked by others as revealed by a mean value of 3.08. However, a standard deviation of 0.906 reveal varied responses from the respondents interviewed as far as checking each other work is concerned. The lack of internal checks within an institution is at odds with Chemengich's (2013) recommendation of information processing in which checks are supposed to be instituted to ensure accuracy and completeness of information being processed.

\section{Staff Supervision}

The results presented in table 1 further reveals that the respondents agreed that there is appropriate supervision of junior staff by their seniors. This is revealed by a mean value of 3.47, though it is not significantly far from the "not sure" position. The standard deviation of 0.893 reveals that there were varied responses from the respondents interviewed. The lack of supervision by senior staff is an indication of deficiencies in strategic controls as advocated for by Schelker (2008) which if not addressed may lead to internal control weaknesses.

\section{Action Taken to Address Weaknesses}

Concerning whether there were actions taken to address weaknesses, the results revealed that corrective actions were normally taken to address weaknesses as shown by a mean value of 3.21. However, this value is close to the midpoint position, implying that respondents were almost not sure as to whether corrective action actually taken to address weaknesses within the public sector. However, a significant standard deviation of 1.119 shows that there were varied responses as far as responses to this activity control indicator was concerned. Other researchers such as Roth (2004) and Padilla, et al. (2012) have reported that in many public institutions there were actions that were being taken to address the weaknesses in the system as away of indication of the commitment by management as recommended by Sarbanes-Oxley Act of 2002 (SOX).

\section{Staffs are Trained to Implement Financial Management System}

The findings on this indicator reveal that respondents agreed that staffs were trained to implement financial management system and this is shown by a mean value of 3.34 . However, this seems close to the midpoint of 3 implying that the respondents seemed to appreciate training as an indicator of internal control activities. Nevertheless, a standard deviation of 0.938 , suggests varied responses from respondents as far as staff training in the implementation of financial management systems is concerned. Staff being trained in the use of financial management system is an indication of the commitment of the management to the effectiveness of systems of internal control. This is in agreement with Verschoor's (1999) recommended programs of selection and training of personnel in order to enhance their capacity towards the implementation of financial management system in the public sector.

\section{There is a well developed chart of account}

In regard to whether there was a well developed chart of account, the results suggest that the respondents agreed to a small extent with this indicator of control activity in Mirangine Sub County. This is revealed by a mean of 3.35. However a significant standard deviation of 1.06 suggests that there were varied responses as far as this test was concerned. Having a well developed chart of account is both a strategic control and a financial control tool as recommended by Schelker (2008).

\section{Restriction of Access to Valuable Information}

The results on this test indicate that respondents were almost indifferent as to whether it was impossible for one staff to have access to all valuable information without the consent of senior staff. This is revealed by a mean value of 2.97 , which is very close to the "not sure" position although the standard deviation of 0.971 indicates the respondents varied greatly as far as this test was concerned. This may be an indication of lack of segregation of duties which may impact on the reliability of financial reports recommended by Schelker (2008) and Whittington and Pany (2001).

\section{Controls over Expenditure}

The results revealed that respondents were not sure as to whether controls are in place to exclude incurring expenditure in excess of allocated funds. This is revealed by a mean value of 3.05 which is very close to the average of 3 . However, the deviation of 0.998 suggests varied responses to the test from the respondents interviewed. The finding could be a failure in the monitoring aspect referred to by Hayes, et al (2005). 


\section{Departmental Budgets Review}

The results suggest that respondents disagreed with the test statement that departmental budgets are reviewed with actual expenditure compared with budgets and explanations for the variances obtained. This is revealed by a mean value of 2.89 . However, in as much as respondents disagreed with the test statement, they were tending towards the "not sure" position of 3 . The standard deviation of 1.197 over the same test suggests varied responses from the respondents interviewed. The failure by the Sub County to provide budget reviews is not concurrent with Ray and Pany (2001)'s recommendation for performance reviews where they recommended comparing actual performance with budgets, forecasts and prior period of management.

\section{Security System on Safeguard of Government Assets}

The results suggest that respondents disagreed with the security system ability to identify and safeguard assets of the government. This is revealed by a mean value of 2.51. However, a significant standard deviation of 1.096 suggests that respondents varied greatly in their responses to the test statement. The failure by the system to identify and safeguard assets of the institution does not augur well with Ray and Pany (2001)'s recommendation for physical controls, necessary to provide security over both records and other assets. Similar results have been established by Owizy's study (2011) which recommended that effectiveness of internal controls in government should prepare annual budget promptly and also have adequate expenditure tracking to prevent financial recklessness.

\section{Financial Management of Public Sector}

This section presents the results on the financial management in Mirangine Sub County. Financial management was examined by analyzing data collected under dimensions of financial management and computing for the mean and standard deviation of the responses to the statements categorized under prudence and accountability.

\section{Descriptive Statistics on Financial Management}

Table 2: Mean and standard deviation of Financial Prudence

\begin{tabular}{|c|c|c|c|c|c|}
\hline Prudence & $\mathbf{N}$ & Min. & Max. & Mean & SD \\
\hline Enough cash to meet Sub County obligations & 30 & 1 & 5 & 1.97 & 1.213 \\
\hline Fee dully collected & 30 & 1 & 5 & 2.64 & 1.046 \\
\hline
\end{tabular}

Source: Author (2014)

\section{Cash Availability within the Department}

From the information revealed in table 2, respondents believed that the government departments in Mirangine Sub County did not have enough cash to meet their obligations effectively as and when they fell due. This is revealed by a mean value of 1.97 . However, a significant standard deviation value of 1.213 under the same test revealed varied responses from the respondents interviewed. The lack of cash does not rhyme with Koitaba's (2013) assertion of financial soundness as an indicator of financial management prudence.

\section{Appropriateness of Fee Charges and Levies to Cover Costs}

From table 2, it can be revealed that the fees charged by the departments in Mirangine Sub County for the services offered are not appropriate to cover the costs of running the departments. This is shown by a mean value of 2.59 although the standard deviation of 0.956 under the same test revealed varied responses from the respondents. This has implications on effective service delivery and it may undermine public confidence in the government departments in Mirangine Sub County as previously found out by studies by Symcon (2005) and Wanjau, et al. (2012).

\section{Management of collected Fee and Levies}

From the information collected from respondents in regard to the management of fee collected, it is clear that all fee and levies collected are not well managed. This is revealed by a mean value of 2.64. However, a standard deviation of 1.046 reveals varied responses from the respondents interviewed over the same test. The information revealed could be an explanation as to the inadequacy of the cash position as revealed by the finding under 4.4.1.1. This means that the financial soundness alluded to by Verschoor (1999) may not be achieved possibly due to corruption. Similar findings have been established by Hubbard (2003) and Humpery (2006) who observed that information on the use of levies collected as well as grants received should be prudent. 
Table 3: Mean and Standard Deviation of Accountability

\begin{tabular}{|c|c|c|c|c|c|}
\hline Accountability & $\mathbf{N}$ & Min. & Max. & Mean & SD \\
\hline System identifies receipts and expenditure & 30 & 1 & 5 & 3.000 & 1.054 \\
\hline Assets are managed well & 30 & 1 & 5 & 3.00 & 1.130 \\
\hline
\end{tabular}

Source: Author (2014)

\section{Accounting System Adequately Identifies Receipts and Expenditure}

From table 3, it is clearly evident that, respondent were indifferent as to whether the government department accounting system adequately identifies receipts and expenditures as stipulated in the budget. This is revealed by a mean value of 3.00 which is the "moderate" position according to the Likert scale. However, the standard deviation of 1.054 reveals that, respondents varied in their responses to the indicator of financial accountability. It is also evident that respondent were indifferent as to whether the government department assets were well managed. This is also revealed by a mean value of 3.00 which is the "moderate" position according to the Likert scale. However, the standard deviation of 1.130 reveals that the respondents varied in their responses to this indicator of financial accountability. These findings appears to support the observation by Rosen and Gayer (2010) that sometimes resources are mismanaged and misappropriated by those put in charge to ensure proper and efficient management of the resources to the detriment of the activity for which the resources have been made available

\section{Relationship between Control Activities and Financial Management}

This section presents results on the relationship between control activity (CA) as the dimensions for internal control systems and prudence (Pru.) and accountability (Acc.) as the indicators of effective financial management. The relationship was established through Pearson correlation analysis.

Table 4.1: Pearson's Correlation Analysis

\begin{tabular}{|c|c|c|c|c|}
\hline & & $\begin{array}{c}\text { CA. } \\
\text { Total Score }\end{array}$ & $\begin{array}{l}\text { Prudence. } \\
\text { Total Score }\end{array}$ & $\begin{array}{c}\text { Accountability. } \\
\text { Total Score }\end{array}$ \\
\hline CA Total Score & $\begin{array}{c}\text { Pearson Correlation } \\
\text { Sig. (2 tailed) } \\
\mathrm{N}\end{array}$ & $\begin{array}{ll} & 0.287^{*} \\
.000 & \\
30 & \\
\end{array}$ & $\begin{array}{cc} & 0.293^{*} \\
& .012 \\
30 & \\
\end{array}$ & $0.487 *$ \\
\hline Pru. Total Score & $\begin{array}{l}\text { Pearson Correlation } \\
\text { Sig. (2 tailed) } \\
\text { N }\end{array}$ & $\begin{array}{ll} & 0.394 * \\
.000 & \\
30 & \end{array}$ & 30 & $\begin{array}{l}.000 \\
30\end{array}$ \\
\hline Acc. Total Score & $\begin{array}{l}\text { Pearson Correlation } \\
\text { Sig. (2 tailed) } \\
\text { N }\end{array}$ & $\begin{array}{ll} & 0.348^{*} \\
.000 & \\
30 & \end{array}$ & $\begin{array}{l}0.194^{*} \\
.000^{0}\end{array}$ & 30 \\
\hline
\end{tabular}

Source: Author (2014)

The correlation table presents the relationship between control activities and financial management measured by prudence and accountability. The results show that all the dimensions related positively.

\section{Relationship between Control Activities and Financial Management}

Table 4 above shows that the control activities relates positively with prudence and accountability $(\mathrm{r}=$ $0.394, \mathrm{p}<0.01 ; \mathrm{r}=0.348, \mathrm{p}<0.01)$ respectively. This suggests that control activities relate positively with financial management. The results seem to agree with Willis and Lightle (2002)'s assertion a direct relationship exists between control activities and financial management if control activities are considered as important in setting the tone of the organization.

\subsection{Analysis of Variance (ANOVA)}

Table 5: ANOVA

\begin{tabular}{|l|l|c|c|c|c|c|}
\hline Model & & Sum of Squares & df & Mean Square & F & Sig. \\
\hline \multirow{3}{*}{1} & Regression & 0.863 & 4 & .324 & 1.557 & $.012(\mathrm{a})$ \\
\cline { 2 - 7 } & Residual & 4.184 & 26 & .208 & & \\
\cline { 2 - 7 } & & & & & & \\
\hline
\end{tabular}

The researcher performed ANOVA as shown in table 4.13. The analysis revealed a significance level of 0.012 which shows that the data is ideal for making a conclusion on the population's parameter as the value of significance ( $p$-value) is less than $5 \%$. The calculated value was greater than the critical value $(1.299<1.557)$ an indication that control activities significantly influence financial management in the public sector in 
Mirangine Sub County.

\section{Conclusions}

Based on the findings of the study it is concluded that internal control systems influences financial management of public sector. This effect is supported by the significant positive relationship observed between control activity and financial management in the public sector in Mirangine Sub County. Pearson's correlation coefficients revealed a moderate positive relationship between control activity and financial management. However, control activities had a slightly higher positive significant relationship with financial management. It is further concluded that the public sector in Mirangine Sub County has an effective financial control system as supported by the presence of clear separation of roles, supervision and commitment of management on the implementation of internal controls. However, internal control systems are not well extended to all the departments which has affected their efficiency as revealed by this study. On financial management in Mirangine Sub County, the study concludes that the prudential use of financial resources is not appropriate, although there is improved asset use as well as classification of revenues and expenditures. The final conclusion of this study is that there is a significant positive relationship between internal control system (control activities) and financial management (prudence and accountability).

\section{Recommendations}

Based on the conclusions drawn from the study, several recommendations are made. The study has revealed that the staffing level in the internal audit department is not adequate to cover the entire Mirangine Sub County set up, evidenced by not conducting regular audit activities, not operating efficiently as well as preparing reports irregularly. The study recommends competence staff profiling based on the requirement of internal control systems. The study also recommends that there should be a deliberate attempt by the leadership of Mirangine Sub County to strengthen the management's commitment towards the implementation of internal control systems. Finally, Mirangine Sub County should maintain strong areas of success in the implementation of the existing control activity as per the results of this study to improve financial management. Furthermore, control activities procedures and policies should be regularly revised to ensure they are effective.

\section{Suggestions For Further Research}

From the conclusion drawn from this study, there is still a gap on the extent to which internal controls is a function of financial management in the public sector. Consequently further studies are suggested in the following areas:

i. The influence of ICT on the effective implementation of internal financial control systems and its implication on financial management in the public sector.

ii. A study on the factors influencing effectiveness of internal control systems on financial performance in the public sector.

iii. Further research on the role of internal audit function on organizations in respect social responsibility.

\section{References}

[1]. ACCA. (2010). Advanced Audit and Assurance. Kaplan Publishing.

[2]. Alin, F., de Boer, S., Freer, G., van Ginneken, L., Klaasen, W., \& Mbane, J. R., (2006). How to build a good small NGO, Management Review, 35(1)55-64.

[3]. Allis, R. P. M. (2004). Financial Management: Ratio Analysis Zero to one Million. New York: McGraw-Hill.

[4]. Chemengich, M. K. (2013). Managing strategic change in the public sector. Standard Research Journal of Business Management, $1(1), 1-40$.

[5]. Chioccola, F. \& Muhlstein, C. (2005). Internal Controls and the ISA Program. New York: McGraw-Hill.

[6]. Crawford, D. B. (2000). Levels of Control, the Internal Auditor, 60(2), 59-63.

[7]. Ellis, J. (2000). The who, how, what, where and why on internal audit, university of New England, Internal Audit Unit.

[8]. El-Nafbi, H. M. (2008). The role of public sector audit and financial control systems in safeguarding public funds in Sudan, Journal of Economics \& Administration, 2 (1), 1-11.

[9]. Hayles, R. (2005). Principles of Auditing, London; Pearson Education Limited.

[10]. Hendrickse, R. F. (2008). Governance and Financial Sustainability of NGOs in South Africa. Unpublished Doctorate Thesis.

[11]. Hubbard, K. D. (2003). Understanding Internal Controls; Auditors who can Accurately Interpreted COSO's Internal Control Framework offer Great Value to Management. The Internal Auditor, 6(5), 429-451.

[12]. Jajo, S. (2005). Internal Audit- Internal Controls Internal Audit. 275 HDL center oh university Athens.

[13]. Karanja, J. G., \& Ng'ang'a, E. N. (2014). Factors influencing implementation of integrated management information system in Kenya government ministries. Research Journal of Finance and Accounting, 5(7), 10-18.

[14]. Khoove, R. (2010). Internal Audit and Risk Management Business Advisory Services; Measuring Effectiveness of Internal Audit, Engineering Economics, 5(55) 70-76.

[15]. Koitaba, E. K. (2013). Analysis of factors influencing financial control practices in community based organizations in Baringo County, Kenya. MBA Thesis, Kabarak Public sector in Mirangine Sub County, Kenya.

[16]. Owizy, S. O. (2011). Assessment of effectiveness of internal control in government ministries: A study of Benue State ministry of finance. Unpublished Masters Thesis. Benue State University.

[17]. Padilla, L. M, Staplefoote, S. \& Morganti, S. (2012). Financial Sustainability for Nonprofit Organizations. Rand. 
[18]. Rittenberg, L. E. (2001). A Guide for the Future: Internal Auditing, Accounting Horizons, 15(2), 105-108.

[19]. Roth, J. (2004). Getting to the Heart of the Problem. The Internal Auditor, British Accounting Review, 32(4), 397-414.

[20]. Schelker, M. (2008). Public auditors: Evidence from the US States. Center for Research in Economics, Management and the Arts Working Paper, 4, 1-45.

[21]. Warren, S. (2005). Internal Controls, Internal Auditor, 62(4), 69-73.

[22]. Wanjau, K. N., Muiruri, B. W., \& Ayodo, E. (2012). Factors affecting provisions of service quality in the public health sector: A case of Kenyatta National Hospital. International Journal of Humanities and Social Science, 2(13), 114-125.

[23]. Wanyama, F. O. (2001). Grass root organizations for sustainable development; The Case of Community Based Organizations in Western Kenya. Unpublished Masters Thesis. Moi University.

[24]. Whittington, P. \& Pany, M. (2001). Principles of auditing \& other assurance services. New York: Mc Graw-Kill. 